\title{
Genetic and environmental causes of variation in epigenetic aging across the lifespan
}

Shuai Li ${ }^{1,2,3}$, Tuong L. Nguyen ${ }^{1}$, Ee Ming Wong ${ }^{3,4}$, Pierre-Antoine Dugué ${ }^{1,3,5}$, Gillian S. Dite ${ }^{1}$, Nicola J. Armstrong ${ }^{6}$, Jeffrey M. Craig ${ }^{7}$, Karen A. Mather ${ }^{8,9}$, Perminder S. Sachdev ${ }^{8,9}$, Richard Saffery ${ }^{10}$, Joohon Sung ${ }^{11}$, Qihua Tan ${ }^{12}$, Anbupalam Thalamuthu ${ }^{8}$, Roger L. Milne ${ }^{1,3,5}$, Graham G. Giles ${ }^{1,3,5}$, Melissa C. Southey $3,4,5$ and John L. Hopper ${ }^{* *}$

\begin{abstract}
Background: DNA methylation-based biological age (DNAm age) is an important biomarker for adult health. Studies in specific age ranges have found widely varying results about its genetic and environmental causes of variation. However, these studies are not able to provide a comprehensive view of the causes of variation over the lifespan.

Results: In order to investigate the genetic and environmental causes of DNAm age variation across the lifespan, we pooled genome-wide DNA methylation data for 4217 people aged 0-92 years from 1871 families. DNAm age was calculated using the Horvath epigenetic clock. We estimated familial correlations in DNAm age for monozygotic (MZ) twin, dizygotic (DZ) twin, sibling, parent-offspring, and spouse pairs by cohabitation status. Genetic and environmental variance components models were fitted and compared. We found that twin pair correlations were -0.12 to 0.18 around birth, not different from zero (all $P>0.29$ ). For all pairs of relatives, their correlations increased with time spent living together (all $P<0.02)$ at different rates $(M Z>D Z$ and siblings $>$ parent-offspring; $P<0.001$ ) and decreased with time spent living apart $(P=0.02)$ at similar rates. These correlation patterns were best explained by cohabitationdependent shared environmental factors, the effects of which were 1.41 (95\% confidence interval [CI] 1.16 to 1.66) times greater for MZ pairs than for DZ and sibling pairs, and the latter were $2.03(95 \% \mathrm{Cl} 1.13$ to 9.47) times greater than for parent-offspring pairs. Genetic factors explained $13 \%(95 \% \mathrm{Cl}-10$ to $35 \%)$ of variation $(P=0.27)$. Similar results were found for another two epigenetic clocks, suggesting that our observations are robust to how DNAm age is measured. In addition, results for the other clocks were consistent with there also being a role for prenatal environmental factors in determining their variation.
\end{abstract}

Conclusions: Variation in DNAm age is mostly caused by environmental factors, including those shared to different extents by relatives while living together and whose effects persist into old age. The equal environment assumption of the classic twin study might not hold for epigenetic aging.

Keywords: Aging, Epigenetic aging, Biological age, Epigenetic clock, DNA methylation, Twin study

\footnotetext{
*Correspondence: j.hopper@unimelb.edu.au

${ }^{1}$ Centre for Epidemiology and Biostatistics, Melbourne School

of Population and Global Health, The University of Melbourne, Parkville, VIC 3051, Australia

Full list of author information is available at the end of the article
}

\section{Background}

Epigenetic alteration is considered to be a hallmark of aging [1]. Several measures of biological age based on DNA methylation (DNAm age) have been developed [2, 3 ] and found to be associated with mortality and disease 
risk in adulthood [2-6]. DNAm age, therefore, is potentially an important biomarker for adult health.

Lifestyle factors, disease risk factors, and genetic variants have been reported to be associated with DNAm age [2-4, 7-10]. Pedigree-based and single nucleotide polymorphism (SNP)-based studies have given widely varying estimates of the proportion of variation in DNAm age explained by genetic factors, ranging from 0 to $100 \%$ $[6-9,11-13]$. One possible reason for this is that these studies focused on specific age ranges only. There is also evidence that environmental factors shared within families explain a substantial proportion of variation in the middle age [14]. Individual studies of specific age ranges are not able to provide a comprehensive view of the causes of variation over the lifespan.

We previously pooled DNA methylation data from a variety of twin and family studies in which participants were at different life stages, from birth to older age. We found evidence that variation in genome-wide average methylation is caused to a great extent by prenatal environmental factors, as well as by environmental factors shared by relatives (including spouse pairs) when they cohabit and that these effects can persist at least to some extent across the whole lifetime [15]. If specific age ranges were studied separately, these findings might not have been found.

We have now applied the same approach to investigate the genetic, shared environmental, and individualspecific environmental causes of variation in DNAm age across the lifespan.

\section{Results}

\section{Sample characteristics}

We analyzed genome-wide DNA methylation data from 10 studies (Additional file 1). The total sample included 4217 people aged $0-92$ years from 1871 families, including monozygotic (MZ) twins, dizygotic (DZ) twins, siblings, parents, and spouses (Table 1).

DNAm age was calculated using the Horvath epigenetic clock [12] (https://dnamage.genetics.ucla.edu/ new), as this clock is mostly applicable to our multi-tissue methylation data and study sample including newborns, children, and adults.

DNAm age was moderately to strongly correlated with chronological age within each dataset, with correlations ranging from 0.44 to 0.84 (Fig. 1). The variance of DNAm age increased with chronological age, being small for newborns, greater for adolescents, and relatively constant with age for adults (Fig. 2). A similar pattern was observed for the absolute deviation between DNAm age and chronological age (Table 1). Within each study, MZ and DZ pairs had similar absolute deviations and residuals in DNAm age adjusted for chronological age.

\section{Within-study familial correlations}

Table 2 shows the within-study familial correlation estimates. There was no difference in the correlation between $\mathrm{MZ}$ and $\mathrm{DZ}$ pairs for newborns or adults, but there was a difference $(P<0.001)$ for adolescents: 0.69 (95\% confidence interval $[\mathrm{CI}] 0.63$ to 0.74 ) for MZ pairs and 0.35 ( $95 \%$ CI 0.20 to 0.48$)$ for DZ pairs. For MZ and DZ pairs combined, there was consistent evidence across datasets and tissues that the correlation was around -0.12 to 0.18 at birth and 18 months, not different from zero (all $P>0.29$ ), and about 0.3 to 0.5 for adults (different from zero in seven of eight datasets; all $P<0.01$ ). Across all datasets, the results suggested that twin pair correlations increased with age from birth up until adulthood and were maintained to older age.

The correlation for adolescent sibling pairs was 0.32 (95\% CI 0.20 to 0.42 ), not different from that for adolescent DZ pairs $(P=0.89)$, but less than that for adolescent MZ pairs $(P<0.001)$. Middle-aged sibling pairs were correlated at $0.12(95 \%$ CI 0.02 to 0.22$)$, less than that for adolescent sibling pairs $(P=0.02)$. Parent-offspring pairs were correlated at 0.15 (95\% CI 0.02 to 0.27 ), less than that for pairs of other types of first-degree relatives in the same study, e.g., DZ pairs and sibling pairs (both $P<0.04)$. The spouse-pair correlations were -0.01 ( $95 \%$ $\mathrm{CI}-0.25$ to 0.24$)$ and 0.12 ( $95 \% \mathrm{CI}-0.12$ to 0.35$)$.

From the sensitivity analysis, the familial correlation results were robust to the adjustment for blood cell composition (Additional file 1: Table S1).

\section{Familial correlations across the lifespan}

From modeling the familial correlations for the different types of pairs as a function of their cohabitation status (Additional file 1: Table S2), the estimates of $\theta$ (see "Methods" section for definition) ranged from 0.76 to 1.20 across pairs, none different from 1 (all $P>0.1$ ). We therefore fitted a model with $\theta=1$ for all pairs; the fit was not different from the model above $(P=0.69)$. Under the latter model, the familial correlations increased with time living together at different rates $(P<0.001)$ across pairs. The decreasing rates did not differ across pairs $(P=0.27)$. The correlations for $\mathrm{DZ}$ and sibling pairs were similar $(P=0.13)$, and when combined their correlation was different from that for parent-sibling pairs $(P=0.002)$ even though these pairs are all genetically first-degree relatives, and was smaller than that for the MZ pairs $(P=0.001)$.

We then fitted a model in which DZ and sibling pairs were combined and the decreasing rates were the same across all pairs. The goodness of fit of this model was not inferior to that of the model above $(P=0.14)$, and the model included fewer parameters. Under this model, the familial correlations for MZ, DZ and sibling, 
Table 1 Sample characteristics by study

\begin{tabular}{|c|c|c|c|c|c|c|c|c|}
\hline Study ${ }^{a}$ & $\begin{array}{l}\text { Biological } \\
\text { sample }\end{array}$ & Microarray & $\begin{array}{l}\text { Type of family } \\
\text { members }\end{array}$ & $N$ (females) & $\begin{array}{l}\text { Chronological } \\
\text { age, mean (SD) }\end{array}$ & $\begin{array}{l}\text { DNAm } \\
\text { age, mean } \\
\text { (SD) }\end{array}$ & $\begin{array}{l}\text { Absolute deviation } \\
\text { of DNAm } \\
\text { and chronological } \\
\text { ages, mean (SD) }\end{array}$ & $\begin{array}{l}\text { Epigenetic age } \\
\text { acceleration, } \\
\text { mean (SD) }\end{array}$ \\
\hline \multirow[t]{2}{*}{ PETS EPIC } & \multirow[t]{2}{*}{ Cord blood } & \multirow[t]{2}{*}{ EPIC } & $M Z$ & $46(24)$ & $0(0)$ & $1.1(0.4)$ & $1.15(0.38)$ & $-0.04(0.38)$ \\
\hline & & & DZ & $44(21)$ & $0(0)$ & $1.2(0.4)$ & $1.22(0.43)$ & $0.04(0.43)$ \\
\hline \multirow{2}{*}{$\begin{array}{c}\text { PETS 27K } \\
\text { CMBCS }\end{array}$} & \multirow{2}{*}{$\begin{array}{l}\text { Cord blood } \\
\text { mononuclear } \\
\text { cells (CMBCs) }\end{array}$} & \multirow[t]{2}{*}{$27 \mathrm{~K}$} & $M Z$ & $34(18)$ & $0(0)$ & $0.1(0.3)$ & $0.20(0.16)$ & $-0.09(0.25)$ \\
\hline & & & DZ & $18(4)$ & $0(0)$ & $0.3(0.5)$ & $0.35(0.46)$ & $0.16(0.50)$ \\
\hline \multirow{2}{*}{$\begin{array}{l}\text { PETS 27K } \\
\text { HUVECS }\end{array}$} & \multirow{2}{*}{$\begin{array}{l}\text { Human umbili- } \\
\text { cal vascular } \\
\text { endothe- } \\
\text { lial cells } \\
\text { (HUVECs) }\end{array}$} & \multirow[t]{2}{*}{$27 \mathrm{~K}$} & $M Z$ & $26(14)$ & $0(0)$ & $6.2(4.1)$ & $6.15(4.10)$ & $-0.95(4.10)$ \\
\hline & & & $\mathrm{DZ}$ & $16(4)$ & $0(0)$ & $8.6(5.1)$ & $8.64(5.07)$ & $1.54(5.07)$ \\
\hline \multirow{2}{*}{$\begin{array}{l}\text { PETS 27K } \\
\text { placenta }\end{array}$} & \multirow[t]{2}{*}{ Placenta } & \multirow[t]{2}{*}{$27 K$} & $M Z$ & $16(12)$ & $0(0)$ & $0.0(0.2)$ & $0.18(0.10)$ & $0.05(0.21)$ \\
\hline & & & DZ & $12(5)$ & $0(0)$ & $-0.1(0.2)$ & $0.21(0.10)$ & $-0.07(0.21)$ \\
\hline \multirow{2}{*}{$\begin{array}{l}\text { PETS 450K } \\
\text { birth }\end{array}$} & \multirow[t]{2}{*}{ Buccal cells } & \multirow[t]{2}{*}{$450 \mathrm{~K}$} & $M Z$ & $18(8)$ & $0(0)$ & $0.8(0.4)$ & $0.81(0.37)$ & $0.02(0.37)$ \\
\hline & & & $\mathrm{DZ}$ & $10(4)$ & $0(0)$ & $0.8(0.2)$ & $0.75(0.15)$ & $-0.04(0.15)$ \\
\hline \multirow{2}{*}{$\begin{array}{l}\text { PETS 450K } \\
18 \text { months }\end{array}$} & \multirow[t]{2}{*}{ Buccal cells } & \multirow[t]{2}{*}{$450 \mathrm{~K}$} & $M Z$ & $12(6)$ & $1.5(0)$ & $2.2(0.7)$ & $0.73(0.66)$ & $0.10(0.66)$ \\
\hline & & & DZ & $8(2)$ & $1.5(0)$ & $2.0(0.5)$ & $0.49(0.45)$ & $-0.15(0.46)$ \\
\hline \multirow[t]{4}{*}{ BSGS } & \multirow{4}{*}{$\begin{array}{l}\text { Peripheral } \\
\text { blood }\end{array}$} & \multirow[t]{4}{*}{$450 \mathrm{~K}$} & $M Z$ & $134(62)$ & $13.8(1.9)$ & $18.4(3.6)$ & $4.65(2.64)$ & $-0.34(2.68)$ \\
\hline & & & DZ & $222(107)$ & $13.2(2.0)$ & $18.0(3.7)$ & $4.82(2.66)$ & $0.09(2.63)$ \\
\hline & & & Sibling & $119(59)$ & $15.5(2.8)$ & $21.2(4.8)$ & $5.74(2.96)$ & $0.22(2.84)$ \\
\hline & & & $\begin{array}{l}\text { Spouse/par- } \\
\text { ents }\end{array}$ & $139(73)$ & $46.6(5.6)$ & $50.8(5.2)$ & $4.75(3.27)$ & $0.00(3.52)$ \\
\hline \multirow[t]{2}{*}{ E-Risk } & \multirow{2}{*}{$\begin{array}{l}\text { Peripheral } \\
\text { blood }\end{array}$} & \multirow[t]{2}{*}{$450 \mathrm{~K}$} & $M Z$ & $852(414)$ & $18(0)$ & $24.1(3.7)$ & $6.25(3.40)$ & $-0.01(3.67)$ \\
\hline & & & DZ & $612(300)$ & $18(0)$ & $24.1(4.0)$ & $6.38(3.63)$ & $0.03(4.02)$ \\
\hline $\begin{array}{l}\text { DTR younger } \\
\text { adults }\end{array}$ & $\begin{array}{l}\text { Peripheral } \\
\text { blood }\end{array}$ & $450 \mathrm{~K}$ & $M Z$ & $146(66)$ & $33.1(2.0)$ & $32.6(4.8)$ & $3.38(2.71)$ & $0.00(4.31)$ \\
\hline \multirow[t]{3}{*}{ AMDTSS } & \multirow{3}{*}{$\begin{array}{l}\text { Peripheral } \\
\text { blood }\end{array}$} & \multirow[t]{3}{*}{$450 \mathrm{~K}$} & $M Z$ & $132(132)$ & $55.6(8.4)$ & $54.8(6.7)$ & $4.56(3.51)$ & $-0.34(4.58)$ \\
\hline & & & DZ & $132(132)$ & $57.0(7.2)$ & $56.5(6.0)$ & $5.04(3.97)$ & $0.60(5.09)$ \\
\hline & & & Sibling & $215(215)$ & $56.6(8.0)$ & $55.5(6.5)$ & $5.04(3.71)$ & $-0.16(4.92)$ \\
\hline \multirow[t]{2}{*}{ TwinsUK } & Peripheral & $27 K$ & $M Z$ & $66(66)$ & $58.4(9.1)$ & $56.0(8.9)$ & $4.23(3.69)$ & $-0.75(5.10)$ \\
\hline & & & DZ & $86(86)$ & $56.6(7.7)$ & $55.6(8.1)$ & $3.61(2.80)$ & $0.57(4.14)$ \\
\hline MUTHER & Adipose tissue & $450 \mathrm{~K}$ & $M Z$ & $186(186)$ & $61.0(9.3)$ & $58.9(6.1)$ & $4.78(3.79)$ & $-0.19(3.67)$ \\
\hline & & & $\mathrm{DZ}$ & $306(306)$ & $57.4(9.3)$ & $57.3(6.2)$ & $4.51(3.25)$ & $0.12(3.57)$ \\
\hline $\begin{array}{l}\text { DTR older } \\
\text { adults }\end{array}$ & $\begin{array}{l}\text { Peripheral } \\
\text { blood }\end{array}$ & $450 \mathrm{~K}$ & $M Z$ & $154(78)$ & $63.2(4.1)$ & $60.5(6.7)$ & $5.02(3.77)$ & $0.00(5.63)$ \\
\hline OATS & $\begin{array}{l}\text { Peripheral } \\
\text { blood }\end{array}$ & $450 \mathrm{~K}$ & $M Z$ & $216(136)$ & $71.2(6.0)$ & 65.5 (6.6) & $6.67(4.50)$ & $0.00(5.36)$ \\
\hline LSADT 1997 & Peripheral & $450 \mathrm{~K}$ & $M Z$ & $36(22)$ & $76.3(2.0)$ & $71.8(3.7)$ & $5.29(3.12)$ & $-0.25(3.86)$ \\
\hline & ০০ & & DZ & $50(40)$ & $76.2(1.6)$ & $72.2(5.7)$ & $5.62(3.70)$ & $0.18(5.50)$ \\
\hline LSADT 2007 & Peripheral & $450 \mathrm{~K}$ & $M Z$ & $36(22)$ & $86.2(2.0)$ & 79.5 (4.9) & $7.46(4.56)$ & $-0.24(4.85)$ \\
\hline & Notuce & & $\mathrm{DZ}$ & $50(40)$ & $86.1(1.6)$ & $80.0(5.4)$ & $7.13(4.09)$ & $0.18(5.47)$ \\
\hline MCCS & $\begin{array}{l}\text { Peripheral } \\
\text { blood }\end{array}$ & $450 \mathrm{~K}$ & Spouse & $124(62)$ & $60.1(6.2)$ & $59.9(8.1)$ & $4.92(3.88)$ & $0.00(6.19)$ \\
\hline
\end{tabular}

EPIC the HumanMethylationEPIC array, 27K the HumanMethylation27 array, 450K the HumanMethylation450 array, MZ monozygotic twin, DZ dizygotic twin, N sample size, SD standard deviation

a Studies-PETS Peri/postnatal Epigenetic Twins Study, including three datasets measured using the 27K array (using three biological samples), $450 \mathrm{~K}$ array (at two points: at birth and age 18 months), and EPIC array, respectively; BSGS Brisbane System Genetics Study, E-Risk Environmental Risk Longitudinal Twin Study, DTR Danish Twin Registry, in two groups: younger and older adults, AMDTSS Australian Mammographic Density Twins and Sisters Study, MUTHER Multiple Tissue Human Expression Resource Study, OATS Older Australian Twins Study, LSADT Longitudinal Study of Aging Danish Twins, with samples collected at years 1997 and 2007 , respectively, MCCS Melbourne Collaborative Cohort Study 

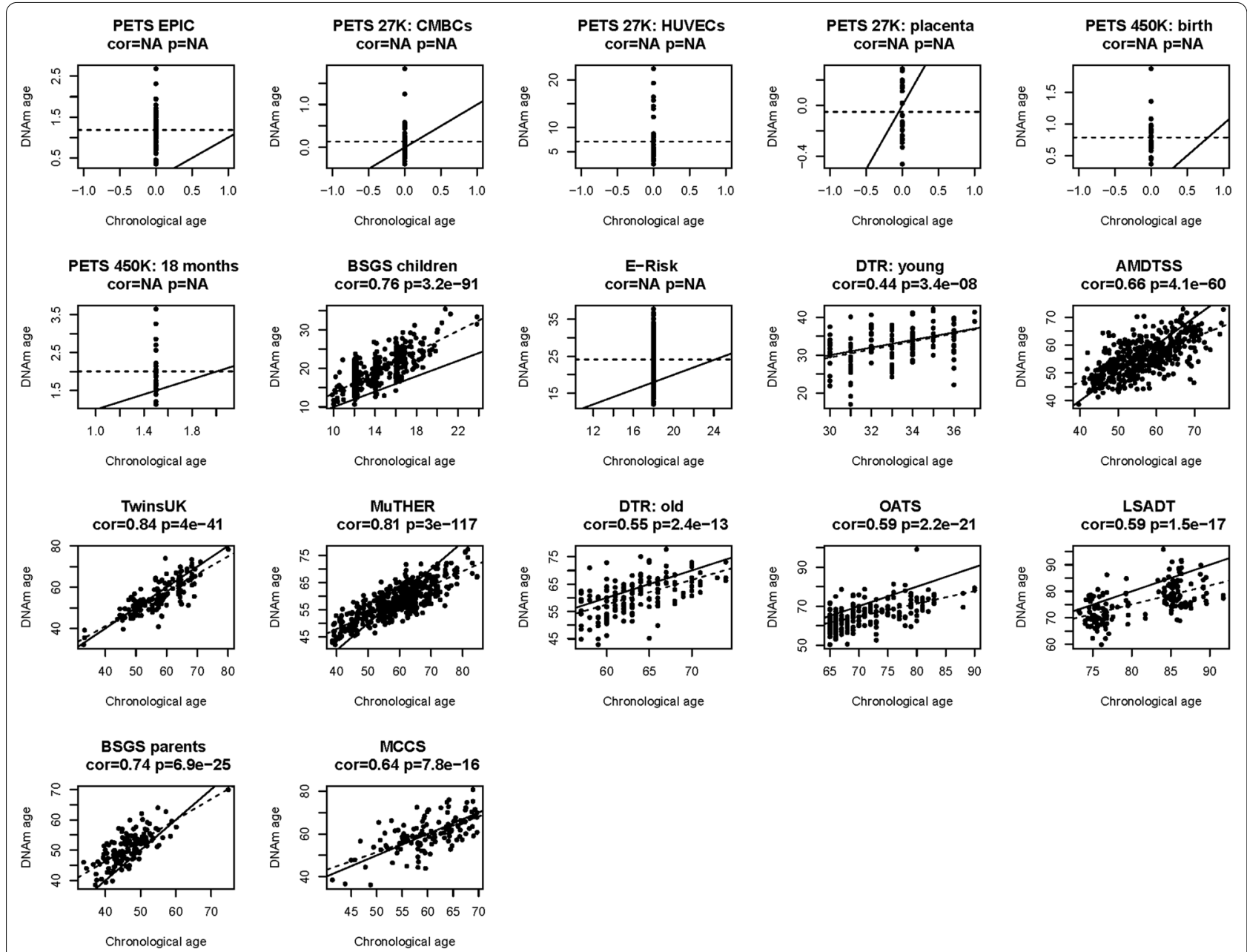

Fig. 1 Correlation between chronological age and DNAm age measured by the epigenetic clock within each study. PETS: Peri/postnatal Epigenetic Twins Study, including three datasets measured using the 27K array, 450K array, and EPIC array, respectively; BSGS: Brisbane System Genetics Study; E-Risk: Environmental Risk Longitudinal Twin Study; DTR: Danish Twin Registry; AMDTSS: Australian Mammographic Density Twins and Sisters Study; MuTHER: Multiple Tissue Human Expression Resource Study; OATS: Older Australian Twins Study; LSADT: Longitudinal Study of Aging Danish Twins; MCCS: Melbourne Collaborative Cohort Study

and parent-offspring pairs all increased with time living together $($ all $P<0.02)$ with different increasing rates $(P<0.001)$; most rapidly for MZ pairs $(\lambda=0.041,95 \%$ CI 0.035 to 0.048 ), less rapidly for DZ and sibling pairs $(\lambda=0.026,95 \%$ CI 0.020 to 0.031$)$, and least rapidly for parent-offspring pairs $(\lambda=0.011,95 \%$ CI 0.002 to $0.0021)$, and decreased with time living apart $(P=0.02)$; see Fig. 3.

\section{Causes of variation across the lifespan}

Results from modeling the causes of variation across the lifespan are shown in Fig. 4 and Additional file 1: Table S3. Under the AE model, additive genetic factors explained 52\% (95\% CI 48 to 53\%) of variation. This, however, was the worst fitting model. Under the cohabitation-dependent $\mathrm{AE}$ model, the effects of genetic factors increased with time living together and decreased with time living apart, and explained minimal variation around birth, $~ 40 \%$ of variation in adolescence and adulthood, and $\sim 50 \%$ of variation at age of 18 years. Under the cohabitation-dependent ACE model, both the effects of genetic factors and the effects of shared environmental factors increased with time living together but did not change with time living apart. The goodness of fits of the cohabitation-dependent $\mathrm{AE}$ and cohabitation-dependent ACE models were similar.

The best-fitting model was the cohabitation-dependent CE model. Under this model, different pairs shared the effects of environmental factors to different extents. The effects for MZ pairs were 1.41 (95\% CI 1.16 to 1.66) times those for $\mathrm{DZ}$ and sibling pairs, and the latter were 2.03 (95\% CI 1.13 to 9.47) times those for parent-offspring 


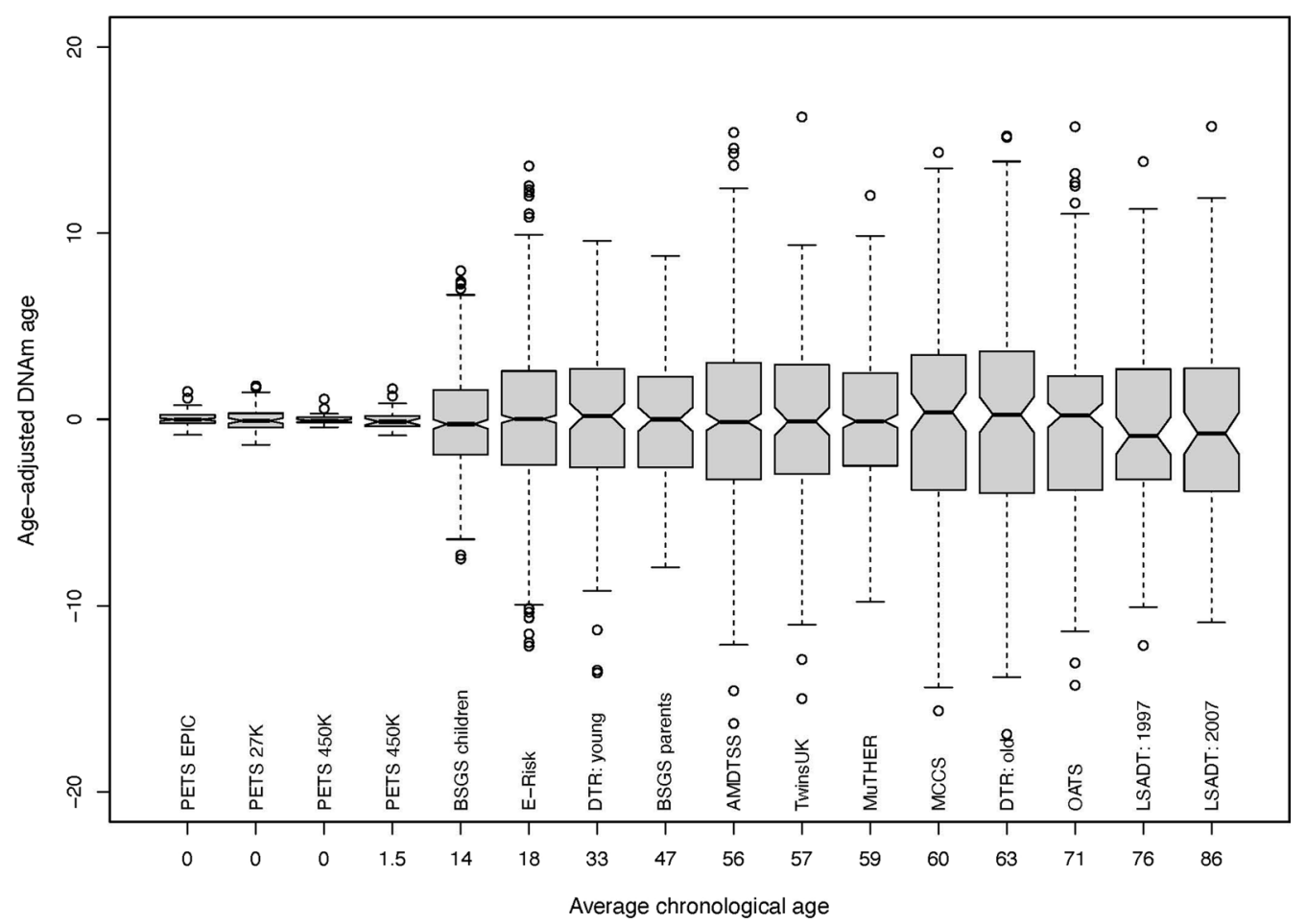

Fig. 2 Variance in age-adjusted DNAm age measured by the epigenetic clock by chronological age. PETS: Peri/postnatal Epigenetic Twins Study, including three datasets measured using the 27K array, 450K array, and EPIC array, respectively; BSGS: Brisbane System Genetics Study; E-Risk: Environmental Risk Longitudinal Twin Study; DTR: Danish Twin Registry; AMDTSS: Australian Mammographic Density Twins and Sisters Study; MuTHER: Multiple Tissue Human Expression Resource Study; OATS: Older Australian Twins Study; LSADT: Longitudinal Study of Aging Danish Twins; MCCS: Melbourne Collaborative Cohort Study

pairs. For all pairs, the proportion of variation explained by shared environmental factors increased with time living together $(P<0.001)$ and decreased at a slower rate with time living apart $(P=0.02)$.

Under the above cohabitation-dependent CE model, we further assumed that the variation is additionally caused by genetic factors whose effects are constant across the lifespan. Genetic factors were estimated to explain $13 \%$ (95\% CI -10 to $35 \%)$ of the variation $(P=0.27)$. That is, after taking into account the existence of non-genetic cohabitation-dependent effects, there was no evidence for a substantive role of genetic factors.

\section{Results for other DNAm age measures}

We also similarly studied two other DNAm age measures, a skin and blood clock developed by Horvath et al. [16] and a blood clock developed by Han et al. [17], which are also developed across tissues and/or ages. Overall, DNAm ages predicted by the two measures appeared to be more similar to chronological age than the DNAm age predicted by the Horvath epigenetic clock: within the same study, they had higher correlations with chronological age (Additional file 2: Figure S1, Additional file 3: Figure S2) and lower absolute deviations from chronological age (Additional file 1: Table S4). For both measures, MZ and DZ pairs had similar absolute deviations and residuals in DNAm age adjusted for chronological age. Similar to the DNAm age predicted by the Horvath epigenetic clock, the variance of the DNAm ages predicted by the two measures increased with age in early life and remained relatively constant with age in adulthood (Additional file 4: Figure S3, Additional file 5: Figure S4).

Additional file 1: Table S5 shows the within-study familial correlation results for the two measures. For both measures, similar results to those for the Horvath epigenetic clock were observed: twin pair correlations increased with age from birth to adulthood and decreased with age in adulthood; no evidence that the twin-pair correlations differed by zygosity was observed across the lifespan, except in adolescence and at age 18 years. For both measures, newborn twins were 
Table 2 Within-study familial correlations in DNAm age

\begin{tabular}{|c|c|c|c|c|c|c|}
\hline Study ${ }^{a}$ & Type of pairs & $\begin{array}{l}\text { Number } \\
\text { of pairs }\end{array}$ & Mean age & Correlation $(95 \% \mathrm{Cl})$ & $P$ & $P$ for $M Z$ versus $D Z$ \\
\hline \multirow[t]{3}{*}{ PETS EPIC } & $M Z$ & 23 & 0 & $0.18(-0.28$ to 0.57$)$ & 0.45 & 0.57 \\
\hline & $\mathrm{DZ}$ & 22 & 0 & $0.01(-0.35$ to 0.36$)$ & 0.98 & \\
\hline & $\mathrm{MZ}$ and $\mathrm{DZ}$ & 45 & 0 & $0.15(-0.22$ to 0.34$)$ & 0.64 & \\
\hline \multirow[t]{3}{*}{ PETS 27K } & $M Z$ & 22 & 0 & $0.35(-0.04$ to 0.64$)$ & 0.85 & 0.69 \\
\hline & DZ & 11 & 0 & $0.00(-0.46$ to 0.46$)$ & 0.09 & \\
\hline & $\mathrm{MZ}$ and $\mathrm{DZ}$ & 33 & 0 & $0.18(-0.15$ to 0.47$)$ & 0.76 & \\
\hline \multirow[t]{3}{*}{ PETS 450K birth } & $M Z$ & 9 & 0 & $-0.05(-0.51$ to 0.43$)$ & 0.09 & 0.29 \\
\hline & $\mathrm{DZ}$ & 5 & 0 & 0.62 (0.01 to 0.89 ) & 0.99 & \\
\hline & MZ and DZ & 14 & 0 & $-0.08(-0.54$ to 0.41$)$ & 0.29 & \\
\hline \multirow[t]{3}{*}{ PETS 450K 18 months } & $M Z$ & 6 & 1.5 & $-0.06(-0.62$ to 0.55$)$ & 0.87 & 0.58 \\
\hline & $\mathrm{DZ}$ & 4 & 1.5 & $-0.52(-0.91$ to 0.40$)$ & 0.31 & \\
\hline & $\mathrm{MZ}$ and DZ & 10 & 1.5 & $-0.12(-0.62$ to 0.46$)$ & 0.71 & \\
\hline \multirow[t]{5}{*}{ BSGS } & $M Z$ & 67 & 13.8 & 0.69 (0.63 to 0.74$)$ & $<0.001$ & $<0.001$ \\
\hline & $\mathrm{DZ}$ & 111 & 13.2 & 0.35 (0.20 to 0.48 ) & $<0.001$ & \\
\hline & Siblings & 260 & 14.0 & 0.32 (0.20 to 0.42 ) & $<0.001$ & \\
\hline & Parent-offspring & 363 & 13.4 & 0.15 (0.02 to 0.27 ) & 0.02 & \\
\hline & Spouses & 59 & 46.6 & $-0.01(-0.25$ to 0.24$)$ & 0.96 & \\
\hline \multirow[t]{3}{*}{ E-Risk } & $M Z$ & 426 & 18.0 & 0.46 (0.40 to 0.52 ) & $<0.001$ & 0.28 \\
\hline & $\mathrm{DZ}$ & 306 & 18.0 & 0.40 (0.33 to 0.47$)$ & $<0.001$ & \\
\hline & $M Z$ and DZ & 732 & 18.0 & 0.43 (0.39 to 0.48 ) & $<0.001$ & \\
\hline DTR younger adults & $M Z$ & 73 & 33.1 & 0.62 (0.52 to 0.70$)$ & $<0.001$ & - \\
\hline \multirow[t]{4}{*}{ AMDTSS } & $M Z$ & 66 & 55.6 & 0.43 (0.26 to 0.58$)$ & $<0.001$ & 0.20 \\
\hline & $\mathrm{DZ}$ & 66 & 57.0 & 0.24 (0.04 to 0.42 ) & 0.02 & \\
\hline & $\mathrm{MZ}$ and DZ & 132 & 56.3 & 0.32 (0.18 to 0.45 ) & $<0.001$ & \\
\hline & Siblings & 552 & 56.4 & 0.12 (0.02 to 0.22 ) & 0.02 & \\
\hline \multirow[t]{3}{*}{ TwinsUK } & $M Z$ & 33 & 55.3 & $0.23(-0.03$ to 0.46$)$ & 0.09 & 0.41 \\
\hline & $\mathrm{DZ}$ & 43 & 59.2 & $0.04(-0.33$ to 0.39$)$ & 0.85 & \\
\hline & $\mathrm{MZ}$ and DZ & 76 & 57.5 & $0.12(-0.07$ to 0.37$)$ & 0.17 & \\
\hline \multirow[t]{3}{*}{ MUTHER } & $M Z$ & 93 & 58.4 & 0.54 (0.44 to 0.63 ) & $<0.001$ & 0.08 \\
\hline & $\mathrm{DZ}$ & 153 & 56.6 & 0.37 (0.25 to 0.48$)$ & $<0.001$ & \\
\hline & $\mathrm{MZ}$ and $\mathrm{DZ}$ & 246 & 57.3 & 0.44 (0.36 to 0.52 ) & $<0.001$ & \\
\hline DTR older adults & $M Z$ & 77 & 63.2 & 0.55 (0.43 to 0.65$)$ & $<0.001$ & - \\
\hline OATS & $M Z$ & 108 & 71.2 & 0.40 (0.26 to 0.53$)$ & $<0.001$ & - \\
\hline \multirow[t]{3}{*}{ LSADT 1997} & $M Z$ & 18 & 76.3 & $0.04(-0.66$ to 0.70$)$ & 0.93 & 0.36 \\
\hline & $\mathrm{DZ}$ & 25 & 76.2 & 0.39 (0.14 to 0.60$)$ & $<0.001$ & \\
\hline & $\mathrm{MZ}$ and DZ & 43 & 76.2 & 0.34 (0.09 to 0.55 ) & 0.01 & \\
\hline \multirow[t]{3}{*}{ LSADT 2007} & $M Z$ & 18 & 86.2 & 0.41 (0.05 to 0.68 ) & 0.04 & 0.95 \\
\hline & $\mathrm{DZ}$ & 25 & 86.1 & 0.40 (0.11 to 0.62 ) & 0.01 & \\
\hline & $\mathrm{MZ}$ and $\mathrm{DZ}$ & 43 & 86.1 & 0.40 (0.17 to 0.59 ) & $<0.001$ & \\
\hline MCCS & Spouses & 62 & 60.1 & $0.12(-0.12$ to 0.35$)$ & 0.33 & - \\
\hline
\end{tabular}

$M Z$ monozygotic twin, DZ dizygotic twin, $C l$ confidence interval

a Studies_PETS Peri/postnatal Epigenetic Twins Study, including three datasets measured using the $27 \mathrm{~K}$ array, $450 \mathrm{~K}$ array (at two points: at birth and age 18 months), and EPIC array, respectively; BSGS Brisbane System Genetics Study; E-Risk Environmental Risk Longitudinal Twin Study, DTR Danish Twin Registry, in two groups: younger and older adults, AMDTSS Australian Mammographic Density Twins and Sisters Study, MuTHER Multiple Tissue Human Expression Resource Study, OATS Older Australian Twins Study, LSADT Longitudinal Study of Aging Danish Twins, with samples collected at years 1997 and 2007 , respectively, MCCS Melbourne Collaborative Cohort Study 


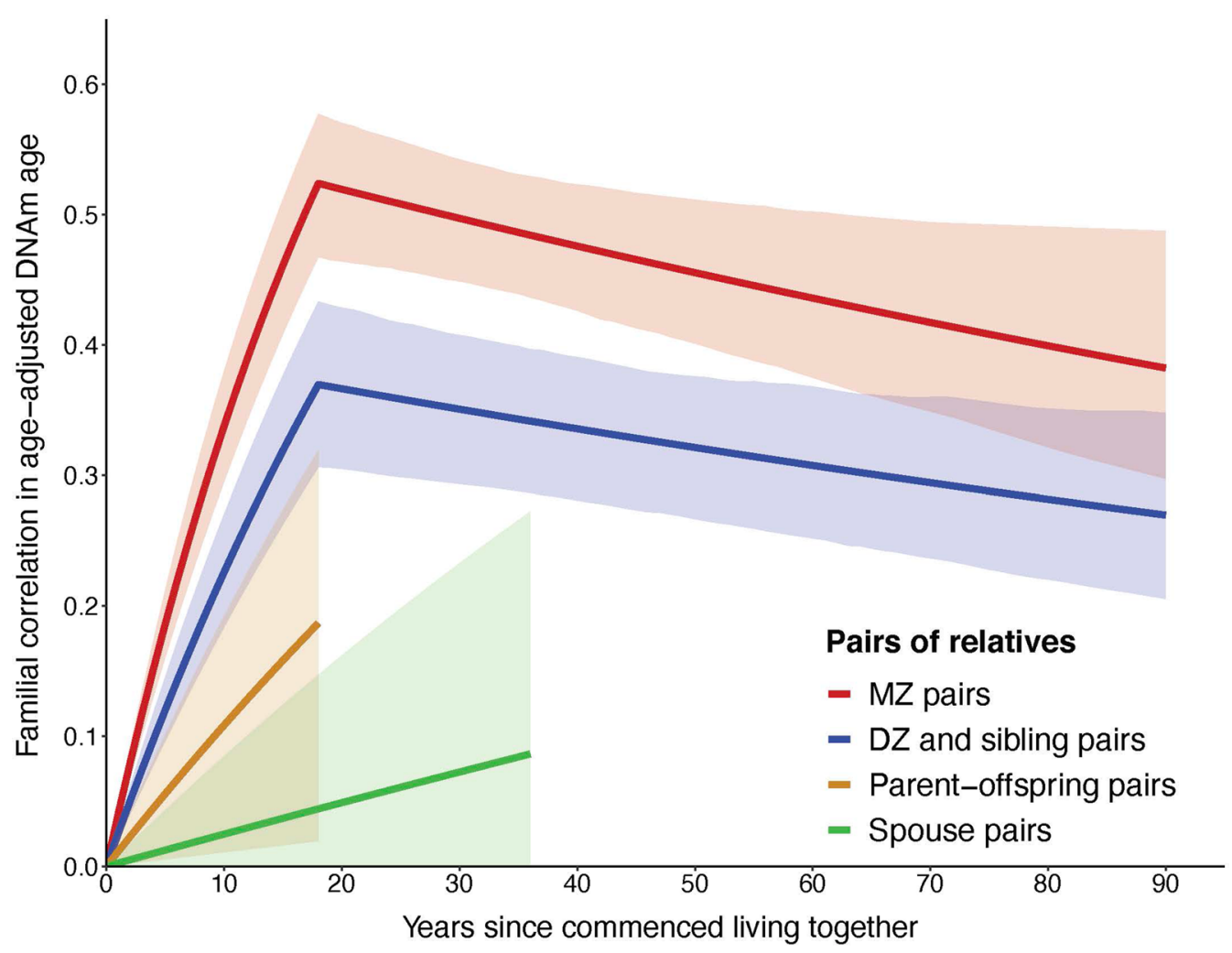

Fig. 3 Familial correlations in DNAm age measured by the epigenetic clock for the different types of pairs across the lifespan. Lines are the predicted familial correlations from modeling the familial correlation as a function of cohabitation status, and shadows are the corresponding $95 \%$ confidence intervals. MZ monozygotic twin, DZ dizygotic twin

found to be correlated at $\sim 0.4$, different from zero (both $P<0.002$ ) but not different by zygosity (both $P>0.1$ ).

\section{Discussion}

Our study provides novel insights into the causes of variation in DNAm age across the lifespan, which appear to be almost entirely environmental (i.e. non-genetic) factors. These include cohabitation-related environmental factors that are evident prior to adulthood, and whose effects persist across the whole of the lifespan. Two longitudinal studies have also found that DNAm age is largely set before adulthood [18].

Our data suggest that people in the same family are not correlated in DNAm age when they start cohabiting; the longer they live together, the more similar they become but at a rate that differs substantially depending on their relationship. This is likely due to the different types of relatives sharing environmental factors relevant to DNAm age to different degrees. When pairs of relatives live apart, they no longer share the cohabitation environment, and this is reflected by a slow dissipation of the effects of shared environmental factors across adulthood at a rate that appears to be similar for all pairs.
Our study is the first to provide a comprehensive view of the genetic and environmental causes of DNAm age variation across the lifespan. Focusing on limited age ranges or types of relatives might bias the interpretation for the causes. For example, if middle-aged (e.g., 40-70 years old) twins only (i.e., no siblings, parents or spouses) were studied, the higher MZ pair correlation compared with DZ pair correlation at that age range (see Fig. 3) might have been interpreted as being caused by genetic factors to some extent, as there are no data from other age ranges or types of relatives contributing to the interpretation. Without using data of various types of relatives whose ages cover the whole lifespan, the comprehensive view would have not been easily obtained.

For MZ pairs, some DNA methylation measures have been found to be similar at birth but divergent over the lifetime, a phenomenon called 'epigenetic drift' $[15,19]$. DNAm age, however, shows a different pattern; MZ pairs are not similar at birth (and neither are DZ pairs) but become more similar the longer they live together, and do so more rapidly than do DZ or other pairs of relatives. In adulthood, MZ pairs then appear to slowly become less similar in DNAm age the longer they live apart, at the 

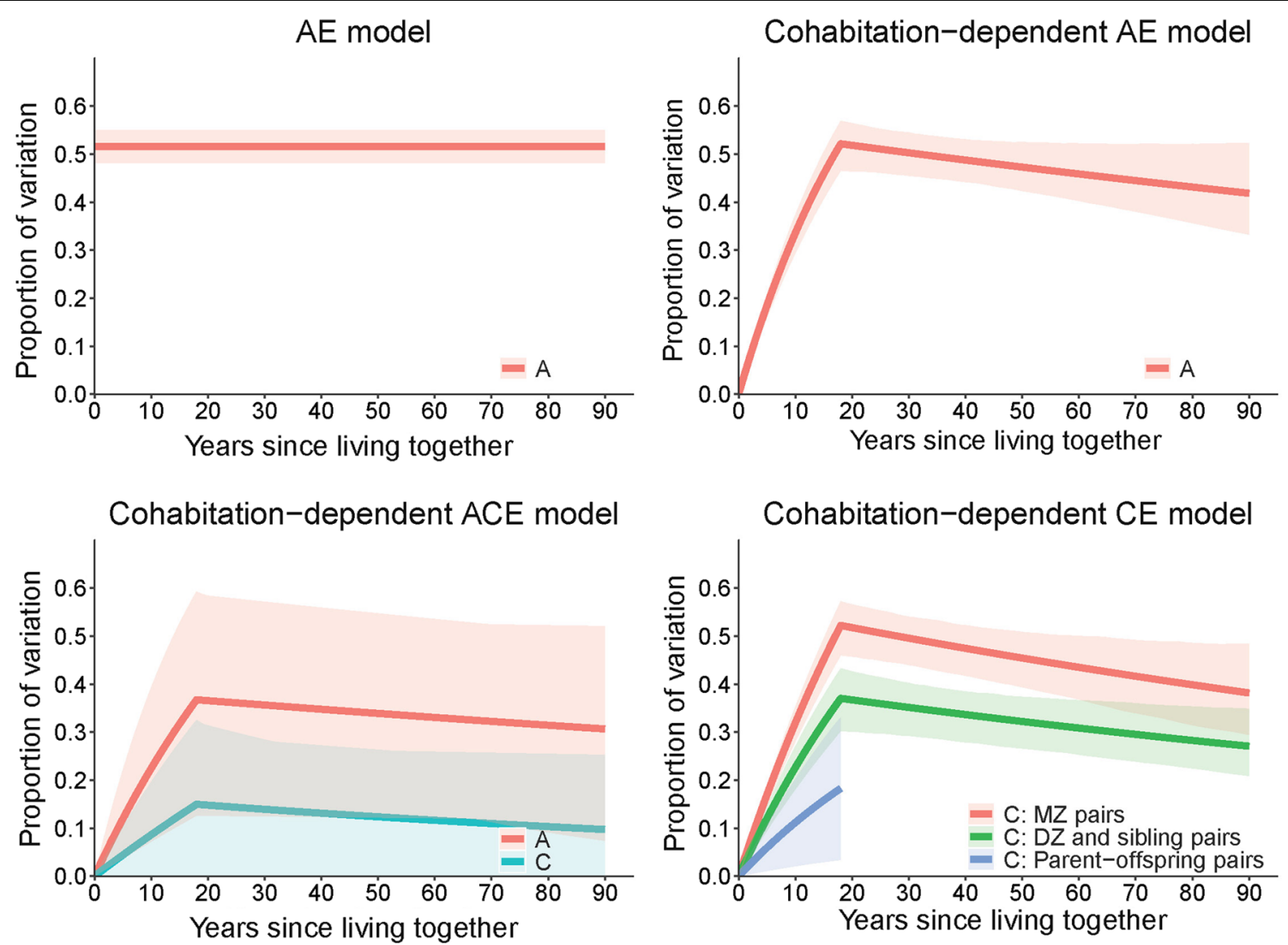

Fig. 4 Proportion of variation in DNAm age measured by the epigenetic clock across the lifespan explained by genetic and environmental factors. Lines are the predicted proportions of variation explained by genetic and environmental factors from the variance components modeling, and shadows are the corresponding 95\% confidence intervals. A: additive genetic factors; C: shared environmental factors; E: individual-specific environmental factors; MZ monozygotic twin, DZ Dizygotic twin. Model details_AE model: variation was assumed to be caused by only A and E, and the effects of $A$ are constant across the lifespan; cohabitation-dependent AE model: variation was assumed to be caused by only $A$ and $E$, and the effects of A depend on cohabitation; cohabitation-dependent ACE model: variation was assumed to be caused by A, C and E, and the effects of $A$ and $C$ both depend on cohabitation; cohabitation-dependent CE model: variation was assumed to be caused by only $C$ and $E$, and the effects of $\mathrm{C}$ depend on cohabitation

same rate as for other pairs of relatives, but still maintain a substantial similarity even into late life. These observations suggest that DNAm age reflects biological aging processes beyond what is reflected by DNA methylation alone.

Our finding that environmental factors shared while cohabiting play a major role in determining the variation in DNAm age is also supported by the observation that the variance of DNAm age increased dramatically with age prior to adulthood and was relatively stable across adulthood (Fig. 2, Additional file 4: Fgiure S3, Additional file 5: Figure S4). The latter has also been found by previous studies [18].

We investigated DNAm age based on other two pantissue/age clocks and found similar results to those for the Horvath clock. These results imply the role of cohabitation-related environmental factors in influencing the variation in these two clocks as well and suggest that our findings are robust to the way DNAm age is measured. These results of newborn MZ and DZ pairs were not differentially correlated in the two clocks implying the additional role of prenatal environmental factors in influencing the variation in these clocks, similar to what we found for the genome-wide average DNA methylation [15].

Given DNAm age has been found to be associated with the risks of death and various diseases in adulthood, identifying the environmental factors affecting DNAm age prior to adulthood might give novel insights into which, and how, early-life factors impact late-life health outcomes. This would have obvious implications for prevention and its timing. There is some evidence that DNAm age is associated with physical developmental characteristics, and exposures to stress and violence for children, although most studies had a moderate sample size [20-24]. 
The classic twin design assumes that MZ and DZ pairs share environmental effects relevant to the trait of interest to exactly the same extent, i.e., the equal environment assumption. Our study shows that this assumption might not hold for DNAm age because there was strong evidence that $M Z$ and $D Z$ pairs share their pre-adult environmental effects to different extents. Furthermore, DZ and sibling pairs were more correlated than parent-offspring pairs, despite all being genetically first-degree relatives of one another; this is not consistent with the correlations predicted by additive genetic factors. Given there is no substantive evidence of genetic effects, our results are not consistent with gene-environment interaction either [25]; we found that models including genetic effects, no matter whether as constant or cohabitationdependent, were less consistent with the data compared with the cohabitation-CE model.

Previous twin and pedigree studies assumed the equal environment assumption holds perfectly and consequently reported the heritability of DNAm age to be $\sim 40 \%$ in adolescence and middle age $[6,9,12]$. Note that under our cohabitation-dependent $\mathrm{AE}$ model (which makes the equal environment assumption), genetic factors would explain $\sim 40 \%$ of variation in adolescence and middle age. This model, however, was not a good fit and was rejected in favor of models that included cohabitation-dependent environmental effects.

Studies have predicted that measured SNPs could explain $0-70 \%$ of variation in DNAm age measured from whole blood and brain tissue [7-9, 11]. Those analyses explicitly assumed, however, that all of the phenotypic covariance is due to genetic factors. In particular, one study predicted the SNP-based heritability of DNAm age based on mothers and children increased with the children's age, being zero when the children were around birth and 37\% when the children were 15 years old [7]in line with our data and the estimates under the cohabitation-dependent AE model that was rejected. Without relying on the equal environment assumption, we found that genetic factors explained at most a small, and not statistically significant, proportion $(\sim 10 \%)$ of variation. Therefore, studies using the equal environment assumption might have overestimated the influence of genetic factors on DNAm age variation.

Our study has several strengths. One strength is that we have included participants whose ages covered the whole lifespan, so we could provide insights into the genetic and environmental causes of DNAm age variation which are unable to be provided by studies focusing on specific ages only. The other strength is that we have substantial sample size, even within studies, so we can detect moderate correlations with good precision, and have the power to distinguish between different variance components models. Our findings should be interpreted with caution, given that they are from statistical modeling which alone cannot prove that a consistent model is a true representation of nature. All that can be said is whether or not the data 'are consistent with' a particular explanation. Nonetheless, statistical modeling is an attempt to identify the plausible and implausible explanations of data, and our results suggest that cohabitation environmental factors being shared by pairs of relatives to different extents are more plausible than genetic explanations.

\section{Conclusions}

The variation in epigenetic aging across the lifespan is most consistent with having been caused, at least to a large extent, by environmental factors, including those shared to different extents by relatives while living together. The effects of the cohabitation environment increase with the time living together and persist into old age. The equal environment assumption of the classic twin study might not hold for epigenetic aging. Given the relationships between DNAm age and health outcomes, these findings highlight the importance and potential of pre-adulthood prevention related to environmental factors for adult diseases and biological aging.

\section{Methods \\ Study sample}

We analyzed genome-wide DNA methylation data from 10 studies, most of which were accessed through public repositories: Peri/postnatal Epigenetic Twins Study (PETS), Brisbane System Genetics Study (BSGS), Environmental Risk Longitudinal Twin Study (E-Risk), Danish Twin Registry (DTR), Australian Mammographic Density Twins and Sisters Study (AMDTSS), TwinsUK cohort, Multiple Tissue Human Expression Resource (MuTHER) Study, Older Australian Twins Study (OATS), Longitudinal Study of Aging Danish Twins (LSADT), and Melbourne Collaborative Cohort Study (MCCS). The total sample included 4217 people aged 0-92 years from 1871 families. Most studies measured methylation using DNA extracted from peripheral blood and the HumanMethylation450 array (Table 1 and Additional file 1).

\section{Data preprocessing}

As several datasets on public repositories contained quality-controlled and preprocessed data only, we were unable to apply the same preprocessing methods across datasets. We used the study-specific data preprocessing methods to address study-specific technical variations. This design allows us to investigate true biological signals independent of any bias introduced from a unifying data preprocessing approach. In DNAm age calculation, 
we chose the 'Normalize Data' option of the online calculator to normalize each dataset to be comparable to the training data of this epigenetic clock.

\section{DNAm age and epigenetic age acceleration}

We used the Horvath epigenetic clock [12] to determine DNAm age (https://dnamage.genetics.ucla.edu/new) because it was developed across tissues and ages, and the 353 methylation sites used by this clock are common to the three methylation arrays used by the 10 studies (Table 1 ).

To adjust for the effects of chronological age on DNAm age, we studied epigenetic age acceleration, calculated as the residuals from a linear regression of DNAm age on chronological age. This calculation was done for each longitudinal measurement of the PETS 450K dataset and of the LSADT, for each generation of the BSGS, and for each age group of the DTR. For the PETS 27K dataset, DNAm age was standardized to have zero mean and unit variance for each type of biological sample, and the average standardized DNAm age across biological samples was used to calculate epigenetic age acceleration.

Sensitivity analyses were performed using only those studies in which DNA methylation was measured in blood to examine the robustness of results to cell composition. Naive CD8 $+\mathrm{T}$ cells, exhausted CD8 $+\mathrm{T}$ cells, plasmablasts, CD4+ T cells, natural killer cells, monocytes, and granulocytes estimated from the DNA methylation data $[12,26]$ were additionally adjusted for in calculating epigenetic age acceleration.

We studied two other DNAm age measures which were developed across tissues and/or ages too, so they might be also applicable to our data. One is the skin and blood clock developed using multi-tissue methylation data fit variance components models. The likelihood ratio test was used to compare nested models. All $P$ values were twosided, and $P<0.05$ was considered significant.

According to the pattern in familial correlations by chronological age, and following previous theoretical and empirical studies $[15,27,30]$, the familial correlations across the lifespan were modeled as a function of the cohabitation status of the pair. The modeling was performed using the pooled data across all studies. Studyspecific variance in the residuals was used in analysis. For individuals $i$ and $j$ from the same family, their correlation was modeled as

$$
\rho_{i j}= \begin{cases}\theta-\mathrm{e}^{-\lambda t} & \text { if } \mathrm{t} \leq \mathrm{t}_{0} \\ \left(\theta-\mathrm{e}^{-\lambda t_{0}}\right) \mathrm{e}^{-v\left(t-t_{0}\right)}, & \text { if } \mathrm{t}>\mathrm{t}_{0}\end{cases}
$$

where $0 \leq \theta \leq 2$, and $\lambda, v \geq 0$.

Under this model, the correlation when the pairs start to live together is $\theta$ minus 1 , and $\lambda$ and $v$ reflect the increasing and decreasing rates at which the familial correlation increases with the length of cohabitation and decreases with the length of separation, respectively. The definitions of $t$ and $t_{0}$ depend on the relationship between $i$ and $j:$ (1) for twin pairs, $t=$ chronological age and $t_{0}=18$ years; (2) for sibling pairs, $t=$ chronological age of the younger sibling and $t_{0}=$ chronological age of the younger sibling when the older sibling was 18 years old; (3) for parentoffspring pairs, $t=$ chronological age of the offspring and $t_{0}=18$ years; and (4) for spouse pairs, $t=$ time in years since the pair married (assumed to be the average chronological age of the pair minus 24 years) and $t_{0}=$ time in years when the pair became separated (if known).

For individuals $i$ and $j$ from the same family, their covariance was modeled as

$$
\operatorname{COV}_{i j}= \begin{cases}\alpha \sigma_{A}^{2}+\beta_{A}\left(1-\mathrm{e}^{-\lambda_{A} t}\right)+\beta_{C}\left(1-\mathrm{e}^{-\lambda_{C} t}\right) & \text { if } \mathrm{t} \leq \mathrm{t}_{0} \\ \alpha \sigma_{A}^{2}+\beta_{A}\left(1-\mathrm{e}^{-\lambda_{A} t_{0}}\right) \mathrm{e}^{-v_{A}\left(t-t_{0}\right)}+\beta_{C}\left(1-\mathrm{e}^{-\lambda_{C} t_{0}}\right) \mathrm{e}^{-v_{C}\left(t-t_{0}\right)}, & \text { if } \mathrm{t}>\mathrm{t}_{0}\end{cases}
$$

of a sample aged 0-94 years [16]. As some of the 391 methylation sites used by this clock were not included the PETS $450 \mathrm{~K}$ and $27 \mathrm{~K}$ datasets, these datasets were not included in its analysis. The other measure is developed by Han et al. [17] using a sample aged 1-101 years. As the measure is developed using HM450K array blood methylation data, non-blood or $27 \mathrm{~K}$ datasets were not included in its analysis.

\section{Statistical analysis}

Residuals of epigenetic age acceleration adjusted for sex were used in subsequent analyses. We used a multivariate normal model for pedigree analysis $[27,28]$ and the program FISHER [29] to estimate correlations for different types of pairs (MZ, DZ, sibling, parent-offspring and spouse) and to where $\alpha, \beta_{\mathrm{A}}, \beta_{\mathrm{C}}, \lambda_{\mathrm{A}}, \lambda_{\mathrm{C}}, v_{\mathrm{A}}, v_{\mathrm{C}} \geq 0$, and the definitions of $t$ and $t_{0}$ are the same as above.

We assumed that the variation of DNAm age can be caused by combinations of additive genetic factors (A), shared environmental factors $(\mathrm{C})$, and individual-specific environmental factors (E). We assessed model fits using the Akaike information criterion (AIC) for the following models and assumptions:

1 AE model: variation is caused by only $\mathrm{A}$ and $\mathrm{E}$; the effects of $\mathrm{A}$ are constant across the lifespan; $\alpha=2 \times$ kinship coefficient, $\beta_{\mathrm{A}}, \beta_{\mathrm{C}}, \lambda_{\mathrm{A}}, \lambda_{\mathrm{C}}, v_{\mathrm{A}}, v_{\mathrm{C}}=0$, and $\sigma_{\mathrm{A}}{ }^{2}$ is free to be estimated.

2 Cohabitation-dependent $\mathrm{AE}$ model: variation is caused only by A and E; the effects of A depend on 
cohabitation; $\alpha, \sigma_{\mathrm{A}}^{2}, \beta_{\mathrm{C}}, \lambda_{\mathrm{C}}, v_{\mathrm{C}}=0, \beta_{\mathrm{A}}=2 \times$ kinship coefficient, $\lambda_{\mathrm{A}}, v_{\mathrm{A}}=0$ for spouse pairs, and the same and free to be estimated for the other pairs.

3 Cohabitation-dependent ACE model: variation is caused by $\mathrm{A}, \mathrm{C}$ and $\mathrm{E}$; the effects of $\mathrm{A}$ and $\mathrm{C}$ both depend on cohabitation; $\alpha, \sigma_{\mathrm{A}}{ }^{2}=0, \beta_{\mathrm{A}}=2 \times$ kinship coefficient, $\lambda_{\mathrm{A}}, v_{\mathrm{A}}=0$ for spouse pairs, but the same and free to be estimated for the other pairs, $\beta_{C}=1$ for all pairs, $\lambda_{\mathrm{C}}$ and $v_{\mathrm{C}}$ are the same for $\mathrm{MZ}, \mathrm{DZ}$, sibling and parent-offspring pairs and free to be estimated.

4 Cohabitation-dependent CE model: variation is caused by only $\mathrm{C}$ and $\mathrm{E}$; the effects of $\mathrm{C}$ depend on cohabitation; $\alpha, \sigma_{\mathrm{A}}^{2}, \beta_{\mathrm{A}}, \lambda_{\mathrm{A}}, v_{\mathrm{A}}=0, \beta_{\mathrm{C}}=1$ for DZ, sibling pairs and spouse pairs, and free to be estimated for the other pairs, $\lambda_{\mathrm{C}}$ and $v_{\mathrm{C}}$ are the same for MZ, $\mathrm{DZ}$, sibling and parent-offspring pairs and free to be estimated.

Under the above cohabitation-dependent CE model, we further allowed for the role of additive genetic factors whose effects were assumed to be constant across the lifespan. This was made possible by letting $\alpha=2 \times$ kinship coefficient and $\sigma_{\mathrm{A}}^{2} \neq 0, \sigma_{\mathrm{A}}^{2}$ was estimated.

\section{Supplementary information}

Supplementary information accompanies this paper at https://doi. org/10.1186/s13148-020-00950-1.

\section{Additional file 1. Supplementary Methods and Tables.}

Additional file 2: Figure S1. Correlation between chronological age and skin-blood DNAm age within each study. PETS: Peri/postnatal Epigenetic Twins Study; BSGS: Brisbane System Genetics Study; E-Risk: Environmental Risk Longitudinal Twin Study; DTR: Danish Twin Registry; AMDTSS: Australian Mammographic Density Twins and Sisters Study; MuTHER: Multiple Tissue Human Expression Resource Study; OATS: Older Australian Twins Study; LSADT: Longitudinal Study of Aging Danish Twins; MCCS: Melbourne Collaborative Cohort Study.

Additional file 3: Figure S2. Correlation between chronological age and Han's DNAm age within each study. PETS: Peri/postnatal Epigenetic Twins Study; BSGS: Brisbane System Genetics Study; E-Risk: Environmental Risk Longitudinal Twin Study; DTR: Danish Twin Registry; AMDTSS: Australian Mammographic Density Twins and Sisters Study; OATS: Older Australian Twins Study; LSADT: Longitudinal Study of Aging Danish Twins; MCCS: Melbourne Collaborative Cohort Study.

Additional file 4: Figure S3. Variance in age-adjusted skin-blood DNAm age by chronological age. PETS: Peri/postnatal Epigenetic Twins Study; BSGS: Brisbane System Genetics Study; E-Risk: Environmental Risk Longitudinal Twin Study; DTR: Danish Twin Registry; AMDTSS: Australian Mammographic Density Twins and Sisters Study; MuTHER: Multiple Tissue Human Expression Resource Study; OATS: Older Australian Twins Study; LSADT: Longitudinal Study of Aging Danish Twins; MCCS: Melbourne Collaborative Cohort Study.

Additional file 5: Figure S4. Variance in age-adjusted Han's DNAm age by chronological age. PETS: Peri/postnatal Epigenetic Twins Study; BSGS: Brisbane System Genetics Study; E-Risk: Environmental Risk Longitudinal Twin Study; DTR: Danish Twin Registry; AMDTSS: Australian Mammographic Density Twins and Sisters Study; OATS: Older Australian Twins Study; LSADT: Longitudinal Study of Aging Danish Twins; MCCS: Melbourne Collaborative Cohort Study.

\section{Abbreviations}

DNAm: DNA methylation; SNP: Single nucleotide polymorphism; PETS: Peri/ postnatal Epigenetic Twins Study; BSGS: Brisbane System Genetics Study; E-Risk: Environmental Risk Longitudinal Twin Study; DTR: Danish Twin Registry; AMDTSS: Australian Mammographic Density Twins and Sisters Study; MuTHER: Multiple Tissue Human Expression Resource Study; OATS: Older Australian Twins Study; LSADT: Longitudinal Study of Aging Danish Twins Study; MCCS: Melbourne Collaborative Cohort Study; MZ: Monozygotic twin; DZ: Dizygotic twin; A: Additive genetic factors; C: Shared environmental factors; E: Individualspecific environmental factors; AIC: Akaike information criterion.

\section{Acknowledgements}

We thank Dr Allan McRae from The University of Queensland for providing pedigree data of the BSGS. The PETS thanks all of the supportive families who participated in the PETS study throughout the years; amazing research staff, Alicia Clifton, Lada Staskova, Declan Bourke, Matt Bisset, Supriya Raj, Kristal Lau; generous volunteers, Jennifer Snowball, Junisha Raj; the phlebotomists from Royal Children's Hospital pathology department. The OATS thanks the participants for their time and generosity in contributing to this research and acknowledges the contribution of the OATS research team (https://cheba .unsw.edu.au/project/older-australian-twins-study) to this study.

\section{Authors' contributions}

SL \& JLH were involved in study conception and design. SL analyzed the data. SL and JLH drafted the manuscript. PETS—SL, EMW, JMC, RS, MCS and JLH, MCCS-EMW, PAD, GGG, MCS, RLM and JLH, AMDTSS—SL, EMW, TLN, GSD, GGG, MCS and JLH, OATS-NJA, KAM, PSS and AT, DTR and LSADT-QT collected the data. All authors read and approved the final manuscript.

\section{Funding}

This work was supported by grants from the Victorian Cancer Agency (Grant No. ECRF19020), Cancer Council Victoria (Grant No. 180626), and National Health and Medical Research Council (NHMRC, Grant No. 057873). SL is a Victorian Cancer Agency Early Career Research Fellow (ECRF19020). SL and TLN were supported by the Cancer Council Victoria Postdoctoral Research Fellowship and the Picchi Award from the Victorian Comprehensive Cancer Centre. TLN was supported by the Cure Cancer Australia (APP1159399). MCS is a NHMRC Senior Research Fellow (APP1155163). JLH is a NHMRC Senior Principal Research Fellow. The PETS was supported by grants from the NHMRC (Grant No. 1146333 to JC). The AMDTSS was facilitated through access to Twins Research Australia, a national resource supported by a Centre of Research Excellence Grant (Grant No. 1079102) from the NHMRC. The AMDTSS was supported by NHMRC (Grant Nos. 1050561 and 1079102), Cancer Australia and National Breast Cancer Foundation (Grant No. 509307). The OATS was funded by a NHMRC and Australian Research Council (ARC) Strategic Award Grant of the Ageing Well, Ageing Productively Program (Grant No. 401162) and NHMRC Project Grants (Grant Nos. 1045325 and 1085606). The OATS was facilitated through Twins Research Australia, a national resource in part supported by a Centre for Research Excellence Grant (Grant No. 1079102) from the NHMRC. The MCCS cohort recruitment was funded by VicHealth and Cancer Council Victoria. The MCCS was further augmented by NHMRC grants numbers 209057 and 396414 and by infrastructure provided by the Cancer Council Victoria. Additional support was received from NHMRC Project Grant Nos. $1011618,1026892,1027505,1050198$, and 1043616. The MCCS research was in part supported by a Program Grant from the NHMRC (Grant No. 1074383) and an award from Victorian Breast Cancer Research Consortium (PI MCS).

\section{Availability of data and materials}

The datasets (accession number) are available on Gene Expression Omnibus: PETS 27K (GSE36642), PETS 450K (GSE42700), BSGS (GSE56105), E-Risk (GSE105018), DTR (GSE61496), AMDTSS (GSE100227), TwinsUK (GSE58045), LSADT (GSE73115). The MuTHER dataset is available on ArrayExpress under the accession number of E-MTAB-1866.

\section{Ethics approval and consent to participate}

This study was approved by the ethics committee of the University of Melbourne. The included studies were approved by respective ethics committees; see Additional file 1 for each study's approval and consent to participate.

\section{Consent for publication}

Not applicable. 


\section{Competing interests}

GSD receives grant money from Genetic Technologies Ltd. for work that is unrelated to the current paper. The other authors have no competing interests to declare.

\section{Author details}

${ }^{1}$ Centre for Epidemiology and Biostatistics, Melbourne School of Population and Global Health, The University of Melbourne, Parkville, VIC 3051, Australia. ${ }^{2}$ Centre for Cancer Genetic Epidemiology, Department of Public Health and Primary Care, University of Cambridge, Cambridge, UK. ${ }^{3}$ Precision Medicine, School of Clinical Sciences At Monash Health, Monash University, Clayton, VIC, Australia. ${ }^{4}$ Department of Clinical Pathology, The University of Melbourne, Melbourne, VIC, Australia. ${ }^{5}$ Cancer Epidemiology Division, Cancer Council Victoria, Melbourne, Australia. ${ }^{6}$ Mathematics and Statistics, Murdoch University, Perth, WA, Australia. ${ }^{7}$ Centre for Molecular and Medical Research, School of Medicine, Faculty of Health, Deakin University, Waurn Ponds, VIC, Australia. ${ }^{8}$ Centre for Healthy Brain Ageing (CHeBA), School of Psychiatry, University of New South Wales, Sydney, NSW, Australia. ${ }^{9}$ Neuropsychiatric Institute, Prince of Wales Hospital, Randwick, NSW, Australia. ${ }^{10}$ Murdoch Childrens Research Institute, Parkville, VIC, Australia. ${ }^{11}$ Institute of Health and Environment, Seoul National University, 1 Gwanak-ro, Gwanak-gu, Seoul 151-742, Korea. ${ }^{12}$ Epidemiology and Biostatistics, Department of Public Health, University of Southern Denmark, Odense, Denmark.

Received: 6 July 2020 Accepted: 13 October 2020

Published online: 22 October 2020

\section{References}

1. Lopez-Otin C, Blasco MA, Partridge L, Serrano M, Kroemer G. The hallmarks of aging. Cell. 2013;153(6):1194-217.

2. Horvath $\mathrm{S}$, Raj K. DNA methylation-based biomarkers and the epigenetic clock theory of ageing. Nat Rev Genet. 2018;19(6):371-84.

3. Dugué PA, Li S, Hopper JL, Milne RL. DNA methylation-based measures of biological aging. In: Tollefsbol TO, editor. Epigenetics in human disease, vol. 6. London: Academic Press; 2018. p. 39-64

4. Dugué PA, Bassett JK, Joo JE, Baglietto L, Jung CH, Wong EM, et al. Association of DNA methylation-based biological age with health risk factors and overall and cause-specific mortality. Am J Epidemiol. 2018;187(3):529-38.

5. Dugué PA, Bassett JK, Joo JE, Jung CH, Ming Wong E, Moreno-Betancur $M$, et al. DNA methylation-based biological aging and cancer risk and survival: pooled analysis of seven prospective studies. Int J Cancer. 2018;142(8):1611-9.

6. Marioni RE, Shah S, McRae AF, Chen BH, Colicino E, Harris SE, et al. DNA methylation age of blood predicts all-cause mortality in later life. Genome Biol. 2015;16(1):25.

7. Simpkin AJ, Hemani G, Suderman M, Gaunt TR, Lyttleton O, McArdle WL, et al. Prenatal and early life influences on epigenetic age in children: a study of mother-offspring pairs from two cohort studies. Hum Mol Genet. 2016;25(1):191-201

8. Lu AT, Hannon E, Levine ME, Hao K, Crimmins EM, Lunnon K, et al. Genetic variants near MLST8 and DHX57 affect the epigenetic age of the cerebellum. Nat Commun. 2016;7:10561.

9. Lu AT, Xue L, Salfati EL, Chen BH, Ferrucci L, Levy D, et al. GWAS of epigenetic aging rates in blood reveals a critical role for TERT. Nat Commun. 2018;9(1):387.

10. Chen M, Wong EM, Nguyen TL, Dite GS, Stone J, Dugue PA, et al. DNA methylation-based biological age, genome-wide average DNA methylation, and conventional breast cancer risk factors. Sci Rep. 2019;9(1):15055.

11. Levine ME, Lu AT, Bennett DA, Horvath S. Epigenetic age of the prefrontal cortex is associated with neuritic plaques, amyloid load, and
Alzheimer's disease related cognitive functioning. Aging (Albany NY). 2015;7(12):1198-211.

12. Horvath S. DNA methylation age of human tissues and cell types. Genome Biol. 2013;14(10):R115.

13. Gibson J, Russ TC, Clarke TK, Howard DM, Hillary RF, Evans KL, et al. A meta-analysis of genome-wide association studies of epigenetic age acceleration. PLoS Genet. 2019;15(11):e1008104.

14. Li S, Wong EM, Joo JE, Jung CH, Chung J, Apicella C, et al. Genetic and environmental causes of variation in the difference between biological age based on DNA methylation and chronological age for middle-aged women. Twin Res Hum Genet. 2015;18(6):720-6.

15. Li S, Wong EM, Dugue PA, McRae AF, Kim E, Joo JE, et al. Genome-wide average DNA methylation is determined in utero. Int J Epidemiol. 2018:47(3):908-16.

16. Horvath S, Oshima J, Martin GM, Lu AT, Quach A, Cohen H, et al. Epigenetic clock for skin and blood cells applied to Hutchinson Gilford Progeria Syndrome and ex vivo studies. Aging (Albany NY). 2018;10(7):1758-75.

17. Han Y, Franzen J, StiehI T, Gobs M, Kuo CC, Nikolić M, et al. New targeted approaches for epigenetic age predictions. BMC Biol. 2020;18(1):71.

18. Kananen L, Marttila S, Nevalainen T, Kummola L, Junttila I, Mononen N, et al. The trajectory of the blood DNA methylome ageing rate is largely set before adulthood: evidence from two longitudinal studies. Age (Dordr). 2016;38(3):65

19. Fraga MF, Ballestar E, Paz MF, Ropero S, Setien F, Ballestar ML, et al. Epigenetic differences arise during the lifetime of monozygotic twins. Proc Nat Acad Sci U S A. 2005;102(30):10604-9.

20. Simpkin AJ, Howe LD, Tilling K, Gaunt TR, Lyttleton O, McArdle WL, et al. The epigenetic clock and physical development during childhood and adolescence: Iongitudinal analysis from a UK birth cohort. Int J Epidemiol. 2017:46(2):549-58.

21. Davis EG, Humphreys KL, McEwen LM, Sacchet MD, Camacho MC Maclsaac $J L$, et al. Accelerated DNA methylation age in adolescent girls: associations with elevated diurnal cortisol and reduced hippocampal volume. Transl Psychiatry. 2017;7(8):e1223.

22. Jovanovic T, Vance LA, Cross D, Knight AK, Kilaru V, Michopoulos V, et al. Exposure to violence accelerates epigenetic aging in children. Sci Rep. 2017;7(1):8962.

23. Suarez A, Lahti J, Czamara D, Lahti-Pulkkinen M, Girchenko P, Andersson S, et al. The epigenetic clock and pubertal, neuroendocrine, psychiatric, and cognitive outcomes in adolescents. Clin Epigenet. 2018;10(1):96.

24. Binder AM, Corvalan C, Mericq V, Pereira A, Santos JL, Horvath S, et al. Faster ticking rate of the epigenetic clock is associated with faster pubertal development in girls. Epigenetics. 2018;13(1):85-94.

25. Purcell S. Variance components models for gene-environment interaction in twin analysis. Twin Res. 2002;5(6):554-71.

26. Houseman EA, Accomando WP, Koestler DC, Christensen BC, Marsit CJ, Nelson $\mathrm{HH}$, et al. DNA methylation arrays as surrogate measures of cell mixture distribution. BMC Bioinform. 2012;13:86.

27. Hopper JL, Mathews JD. Extensions to multivariate normal models for pedigree analysis. II. Modeling the effect of shared environment in the analysis of variation in blood lead levels. Am J Epidemiol. 1983;117(3):344-55.

28. Hopper JL, Mathews JD. A multivariate normal model for pedigree and longitudinal data and the software 'FISHER.' Aust J Stat. 1994;36(2):153-76.

29. Lange K, Weeks D, Boehnke M. Programs for pedigree analysis: MENDEL, FISHER, and dGENE. Genet Epidemiol. 1988;5(6):471-2.

30. Lange K. Cohabitation, convergence, and environmental covariances. Am J Med Genet. 1986;24(3):483-91.

\section{Publisher's Note}

Springer Nature remains neutral with regard to jurisdictional claims in published maps and institutional affiliations. 